\title{
ANALISIS PENERAPAN ETIKA DAN HUKUM KESEHATAN PADA PEMBERIAN PELAYANAN KESEHATAN DI RUMAH SAKIT NENE MALLOMO KABUPATEN SIDENRENG RAPPANG
}

\section{Analyze of the Application of Ethics and Health Law on the Provision of Health Services at Nene Mallomo Hospital Sidrap Regency}

\author{
Anggie Septie Aningrum AN ${ }^{1}$, Syarifuddin Yusuf ${ }^{2}$, Usman $^{3}$ \\ ${ }^{1}$ Mahasiswa Fakultas Ilmu Kesehatan Universitas Muhammadiyah Parepare \\ ${ }^{2}$ Dosen Program Studi Kesehatan Masyarakat Universitas Muhammadiyah Parepare \\ ${ }^{3}$ Dosen Program Studi Kesehatan Masyarakat Universitas Muhammadiyah Parepare \\ (anggie.an26@yahoo.com)
}

\begin{abstract}
ABSTRAK
Dalam pelayanan kesehatan perilaku petugas kesehatan harus tunduk pada etika profesi (kode etik profesi) dan juga tunduk pada ketentun hukum, aturan, dan perundang-undangan.. Penelitian ini merumuskan masalah yaitu bagaimana pelayanan kesehatan di Rumah Sakit Nene Mallomo Kab.Sidrap, bagaimana penerapan etika dalam pemberian pelayanan kesehatan di Rumah Sakit Nene Mallomo Kab.Sidrap, dan bagaimana penerapan hukum kesehatan dalam pemberian pelayanan kesehatan di Rumah Sakit Nene Mallomo Kab.Sidrap. tujuan dari penelitian ini adalah untuk mengetahui pelayanan kesehatan di Rumah Sakit Nene Mallomo Kab.Sidrap, penerapan etika dalam pemberian pelayanan kesehatan di Rumah Sakit Nene Mallomo Kab.Sidrap, dan mengetahui penerapan hukum kesehatan dalam pemberian pelayanan kesehatan di Rumah Sakit Nene Mallomo Kab.Sidrap.

Penelitian ini dengan metode survei deskriptif yang dilakukan di Rumah Sakit Nene Mallomo Kab. Sidrap menggunakan kuesioner yang diberikan ke sampel yaitu 99 pasien rawat inap yang ditentukan dengan teknik Accidental Sampling. Data diolah dengan bantuan aplikasi SPSS 24 dan di analisis secara univariate sehingga menghasilkan frekuensi distribusi setiap variabel.

Berdasarkan analisis data didapatkan bahwa Pelayanan kesehatan yang diberikan di Rumah Sakit Nene Mallomo Kab.Sidrap dalam kategori memuaskan pasien, penerapan etika dalam pemberian pelayanan kesehatan sudah baik dan sesuai dengan aturan kode etika dan, Penerapan hukum kesehatan dalam pemberian pelayanan di Rumah Sakit Nene Mallomo Kab. Sidrap sudah baik dan sesuai dengan aturan perundang-undangan yang berlaku.
\end{abstract}

\section{Kata Kunci : Etika, Hukum Kesehatan, Pelayanan Kesehatan}

\section{ABSTRACT}

In behavioral health services health workers must be subject to professional ethics (professional code of ethics) and also subject to the law, rules and legislation. This research formulates the problem of how health services at Nene Mallomo Hospital Sidrap Regency, how the application of the health law ini the provision of health services at Nene Mallomo Hospital Sidrap Regency, the application of ethics in the provision of health services at Nene Mallomo Hospital Sidrap Regency and to know the application of the health law in the provision of health services at Nene Mallomo Hospital Sidrap Regency. 
This research uses descriptive survey method conducted at Nene Mallomo Hospital Sidrap Regency uses questionnaire given to a sample of 99 inpatiens determined by Accidental Sampling technique. The data is prossed with the help of SPSS 24 application and analyzed univariate to produce the frequency of distribution of each variable.

Based on data analysis, it was found that the health services provided at Nene Mallomo Hospital in Sidrap Regency were in the category of satisfying patiens, the application of ethics in the provision of health services was good and in accordance with the rules of the ethics code and the application of health law in the provision of services at Nene Mallomo Hospital Sidrap Regency is good and in accordance with the laws and regulations.

Keyword : Ethics, health law, health services

\section{PENDAHULUAN}

Kesehatan merupakan salah satu hal yang sangat mempengaruhi manusia untuk melaksanakan kegiatannya sehari-hari. Tanpa kesehatan manusia tidak akan produktif untuk hidup layak baik secara ekonomi maupun dalam menjalani pendidikan. Kesehatan merupakan hak asasi manusia dan salah satu unsur kesejahteraan yang harus diwujudkan sesuai dengan cita-cita bangsa yang terdapat dalam Pancasila dan Undang-Undang Dasar Negara Republik Indonesia Tahun 1945. Pasal 34 ayat (3) Undang-Undang Dasar 1945 dari hasil amandemen, menyatakan bahwa negara bertanggung jawab atas penyediaan fasilitas pelayanan kesehatan dan fasilitas pelayanan umum yang layak. ${ }^{1}$

Petugas kesehatan dalam hal melayani masyarakat, juga terikat pada etika dan hukum, atau etika dan hukum kesehatan. Dalam pelayanan kesehatan perilaku petugas kesehatan harus tunduk pada etika profesi (kode etik profesi) dan juga tunduk pada ketentun hukum, aturan, dan perundangundangan. Yang mana apabila petugas kesehatan melanggar kode etik profesi maka akan mendapat sanksi etika dari organisasi profesinya dan apabila juga melanggar ketentuan perundang-undangan juga akan mendapat sanksi hukum (pidana atau perdata). ${ }^{2}$

$$
\text { Adapun data menurut Lembaga }
$$

Bantuan Hukum (LBH) Kesehatan menyatakan banyaknya kasus malpraktik di Indonesia adalah akibat sistem kesehatan yang tidak menunjang. Menurut data Yayasan Pemberdayaan Konsumen Kesehatan Indonesia (YPKKI) dari tahun 1998 sampai tahun 2004 telah menangani 255 kasus malpraktik dan jarang diselesaikan sampai tingkat penyidikan yang dikarenakan polisi juga masih tidak paham tentang masalah kesehatan ini dan mengakibatkan penanganan polisi terhadap kasus malapraktik kurang optimal. $^{3}$

Maka dari itu penulis bermaksud mengadakan penelitian tentang "Analisis Penerapan Etika dan Hukum Kesehatan pada Pemberian Pelayanan Kesehatan di Rumah Sakit Nene Mallomo Kab. Sidrap”..

Tujuan dari penelitian ini adalah untuk mengetahui pelayanan kesehatan di Rumah Sakit Nene Mallomo Kab.Sidrap, penerapan etika dalam pemberian pelayanan kesehatan di Rumah Sakit Nene Mallomo Kab.Sidrap, dan 
mengetahui penerapan hukum kesehatan dalam pemberian pelayanan kesehatan di Rumah Sakit Nene Mallomo Kab.Sidrap.

\section{BAHAN DAN METODE}

Penelitian ini dengan metode survei deskriptif yang dilakukan di Rumah Sakit Nene Mallomo Kab. Sidrap menggunakan kuesioner yang diberikan ke sampel yaitu 99 pasien rawat inap yang ditentukan dengan teknik Accidental Sampling. ${ }^{4} \quad$ Variabel independen dalam penelitian ini adalah penerapan etika dan penerapan hukum kesehatan sedangkan variabel dependennya adalah pelayanan kesehatan. Data primer dalam penelitian ini diperoleh diperoleh berdasarkan jawaban kuesioner menurut variabel yang diteliti sedangkan data sekunder diperoleh melalui bagian rekam medik di Rumah Sakit Nene Mallomo terkait jumlah pasien pada tahun 2017.

Data yang telah diolah didapatkan bahwa Pelayanan kesehatan yang diberikan di Rumah Sakit Nene Mallomo Kab.Sidrap dalam kategori memuaskan pasien, penerapan etika dalam pemberian pelayanan kesehatan sudah baik dan sesuai dengan aturan kode etika dan, Penerapan hukum kesehatan dalam pemberian pelayanan di Rumah Sakit Nene Mallomo Kab. Sidrap sudah baik dan sesuai dengan aturan perundang-undangan yang berlaku.

\section{HASIL}

Karakteristik responden berdasarkan umur pada Tabel 1 menunjukkan umur responden dominan pada umur $\leq 15$ tahun dan 16 - 30 tahun masing-masing sebanyak 25 responden $(25,3 \%)$ dan umur terendah $\geq 76$ tahun sebanyak 6 responden $(6,1 \%)$. Distribusi responden berdasarkan jenis kelamin yaitu tertinggi laki-laki sebanyak 41 responden $(41,4 \%)$, dan terendah perempuan sebanyak 58 responden (58,6\%). Distribusi responden berdasarkan tingkat pendidikan pendidikan responden yang tertinggi pada pasien dengan tingkat pendidikan terakhir SMA sebanyak 35 responden $(35,4 \%)$ dan terendah $\mathrm{S} 1$ sebanyak 10 responden $(10,1 \%)$. Distribusi responden berdasarkan pekerjaan yaitu diperoleh pekerjaan responden yang tertinggi yaitu IRT/Tidak Kerja sebanyak 56 responden (56,6\%) dan terendah PNSPeg./Karyawan Swasta sebanyak 6 responden $(6,1 \%)$.

Karakteristik responden berdasarkan ruang perawatan pada Tabel 2 menunjukkan responden berdasarkan ruang perawatan diperoleh ruang perawatan responden tertinggi pasien berada di ruang Mahkota Dewa sebanyak 24 responden $(24,2 \%)$ dan terendah di ruang perawatan Sambiloto sebanyak 10 responden $(10,1 \%)$, Distribusi responden berdasarkan kelas perawatan diperoleh kelas perawatan responden tertinggi berada di kelas VIP sebanyak 26 responden (26,3\%) dan terendah berada di Kelas II sebanyak 22 responden (22,2\%), Distribusi responden berdasarkan jenis perawatan pasien diperoleh jenis perawatan responden tertinggi yaitu interna sebanyak 32 responden $(32,3 \%)$ dan terendah yaitu Bedah sebanyak 10 responden 
(10,1\%). Distribusi responden berdasarkan jenis kepesertaan diperoleh jenis kepesertaan tertinggi responden pasien yang menggunakan JKN/BPJS sebanyak 72 responden $(72,7 \%)$ dan terendah JAMKESDA sebanyak 2 responden $(2,0 \%)$.

\section{PEMBAHASAN}

Penelitian yang dilakukan pada 99 responden, menunjukkan hasil bahwa pelayanan kesehatan pada jawaban responden berdasarkan kuesioner pada saat penelitian dengan kategori puas sebanyak 96 responden (97,0\%), dan kategori tidak puas sebanyak 3 responden $(3,0 \%)$ maka dapat dikatakan jika pelayanan kesehatan di Rumah Sakit Nene Mallomo Kab. Sidrap dalam kategori memuaskan pasien.

Hasil ini dipengaruhi beberapa faktor seperti umur dan tingkat pendidikan responden dimana dominan pada usia yang relatif masih muda sehingga mudah untuk menyikapi, melihat, dan merasakan setiap pelayanan yang telah diberikan baik pada yang secara langsung maupun tidak langsung. Hasil tersebut juga dapat disebabkan bisa didapatkan dari cara penerimaan masing-masing pasien dari apa yang mereka terima dari petugas, perawat, maupun dokter pada saat melakukan pendaftaran, pelayanan, maupun pengobatan serta apa yang masing-masing pasien lihat selama di rawat di Rumah Sakit tersebut. ${ }^{5}$

Jika mengacu pada indikator penilaian yakni pemberian pelayanan yang optimal maka pelayanan kesehatan di rumah sakit tersebut sudah baik karena tidak adanya pengaduhan dari pasien sebelumnya. Selain itu merujuk pada indikator penilaian lain pelayanan kesehatan yang efektif dan efisien sudah terpenuhi di Rumah Sakit Nene Mallomo ini karena berdasarkan pengamatan saat penelitian, para petugas kesehatan sangat sigap dan profesional dalam menangani dan mengatasi keluhan dari pasien. ${ }^{6}$.

Selain dari itu berdasarkan pertanyaan pada kuesioner, responden mengatakan puas pada bagian administrasi karena pasien tidak memerlukan waktu yang lama mulai dari proses pendaftaran sampai penanganan juga tidak ada pasien yang merasa ditelantarkan, kemudian mengenai cara dokter/perawat dalam menangani pasien responden merasa puas karena para petugas menjalankan tugasnya dengan optimal, tepat dan sesuai dengan penanganan yang harus didapatkan pasien, selanjutnya berdasarkan kesigapan dokter/perawat responden banyak yang mengatakan puas karena menurut mereka petugas kesehatan sangat handal dan tanggap dalam menangani pasien terlebih jika dalam keadaan darurat atau jika pasien membutuhkan sesuatu maka petugas kesehatan dengan cepat akan datang untuk memenuhi permintaan pasien. $^{7}$

Karena semua indikator penilaian sebagian besar telah terpenuhi dan juga sejalan dengan hasil olah data yang dilakukan maka dapat dikatakan jika pelayanan kesehatan di Rumah Sakit Nene Mallomo Kab. Sidrap memuaskan pasien. 
Penelitian ini sejalan dengan penelitian yang dilakukan oleh Dahlia Said (2010) yang menyatakan jika pelayanan kesehatan di Rumah Sakit Nene Mallomo Kab. Sidrap masuk dalam kategori memuaskan karena banyaknya masyarakat yang telah memanfaatkan sarana pelayanan kesehatan yang tersedia.

Tetapi hasil penelitian ini tidak sejalan dengan penelitian dari Balitbangda Sulsel di RSU A. Makkasau tentang kepuasan pasien di keempat rumah sakit dipersepsi puas berdasarkan lima dimensi kepuasan. Namun, beberapa sub dimensi masih dipersepsikan buruk oleh pasien seperti perawat yang masih membeda-bedakan dalam pelayanan, kurangnya persediaan alat medis dan non medis, sampai kebersihan lantai kamar mandi dan seprei.

Berdasarkan hasil penelitian yang dilakukan pada 99 responden di dapatkan untuk penerapan etika/kode etik kategori baik sebanyak 98 responden $(99,0 \%)$, dan kategori tidak baik sebanyak 1 responden $(1,0 \%)$ maka dapat dikatakan jika penerapan etika/kode etik dalam pemberian pelayanan Rumah Sakit Nene Mallomo Kab. Sidrap sudah baik.

Hasil tersebut disebabkan berbagai faktor seperti pekerjaan dan jenis perawatan responden yang lebih dominan tidak pekerja yang mana termasuk pensiunan, anak, dan ibu hamil yang mana memang memerlukan pelayanan yang lebih dari petugas kesehatan. Walaupun pada hakikatnya pelayanan kesehatan yang diberikan adalah sama tanpa membedakan karakteristik maupun aspek lain yang dimiliki pasien di Rumah Sakit tersebut. ${ }^{8}$

Berdasarkan pengamatan, cara petugas kesehatan memperlakukan pasien sangat baik dari segi cara berkomunikasi maupun dari gerak tubuh sehingga memberikan kesan sangat baik bagi pasien serta tidak adanya pasien yang merasa didiskriminasikan oleh petugas baik dari segi sikap maupun perlakuan medis yang juga termasuk beberapa kriteria dalam penilaian etika atau kode etik. Selain itu jika dikaitkan dengan indikator penilaian lain seperti penghargaan terhadap pasien, petugas kesehatan juga pihak rumah sakit sangat memperhatikan hak pasien utamanya kenyamanan selama di rawat di Rumah Sakit Nene Mallomo Kab. Sidrap. ${ }^{9}$

Selain itu berdasarkan pertanyaan pada kuesioner, untuk penghargaan tenaga kesehatan terhadap kepentingan pasien banyak responden mengatakan baik karena petugas kesehatan sangat menjaga kepentingan dan privasi pasien yang mana petugas kesehatan menjaga jadwal besuk pasien agar tidak menganggu pasien, kemudian untuk pertanyaan persamaan sikap dan perlakuan petugas kesehatan banyak responden mengatakan baik karena menurut penuturan responden tidak ada pasien yang merasa dibedakan atau dikecualikan dan juga berdasarkan pengamatan petugas kesehatan bersikap sama terhadap pasien baik khususnya dari segi cara komunikasi. ${ }^{10}$

Dengan terpenuhinya beberapa indikator penilaian tersebut yang juga sejalan 
dengan hasil olah data yang dilakukan maka dapat dikatakan jika penerapan etika/kode etik dalam pemberian pelayanan Rumah Sakit Nene Mallomo Kab. Sidrap sudah baik.

Hasil ini sejalan dengan penelitian Sumima (2016) tentang persepsi pasien terhadap penerapan prinsip etika keperawatan menyimpulkan bahwa persepsi pasien berpengaruh terhadap penilaian penerapan etika di Rumah Sakit Cibinong. Penelitian yang dilakukan oleh Ernawati (2010) di bagian rawat inap Rumah Sakit Nene Mallomo memberikan informasi bahwa petugas kesehatan memiliki ketanggapan dalam memenuhi kebutuhan pelayanan dan ketanggapan keluhan pasien dan melaksakan tindakan secara cepat dan tepat. Selain itu penelitian yang dilakukan Prisilia (2015) menyimpulkan bahwa tidak ada perbedaan kualitas pelayanan antara pasien penerima bantuan dengan yang tidak menerima bantuan di RSUP Prof. Dr. R. D. Kandou Manado. ${ }^{11}$

Akan tetapi penelitian yang dilakukan Sumijatun (2014) tentang persepsi terhadap penerapan prinsip etika keperawatan mendapati bahwa penerapan prinsip-prinsip etika keperawatan masih kurang baik. Ini tentu berbanding terbalik dengan hasil yang didapatkan peneliti. ${ }^{12}$

Berdasarkan hasil penelitian yang dilakukan pada 99 responden di dapatkan untuk penerapan hukum kesehatan kategori baik sebanyak 96 responden $(97,0 \%)$, dan kategori tidak baik sebanyak 3 responden $(3,0 \%)$ maka dapat dikatakan jika penerapan hukum kesehatan pada pemberian pelayanan kesehatan di Rumah Sakit Nene Mallomo Kab. Sidrap sudah baik.

Perbedaan hasil tersebut disebabkan berbagai faktor seperti yang bisa didapatkan dari penerimaan masing-masing pasien dan pendapat pasien tentang mekanisme atau prosedur pelaksanaan tindakan medis maupun non medis selama di rawat yang jika dikaitkan dengan indikator penilaian yang ada yakni jumlah tenaga kesehatan yang memadai maka dapat dikatakan sudah terpenuhi berdasarkan penuturan responden jika petugas kesehatan selalu ada di tempat yang juga berkaitan dengan profesionalisme kerja yang dimiliki oleh petugas kesehatan. ${ }^{13}$

Adapun indikator lain yakni kelengkapan sarana dan prasarana juga sudah terpenuhi dikarenakan belum pernah ada kasus penelantaran pasien atau adanya pasien yang tidak tertangani secara optimal di Rumah Sakit ini. Adapun mengenai pelaksanaan ketentuan atau aturan yakni adanya persetujan tindakan medis (Informed Consent) dan pengisian rekam medis sesuai dengan pengakuan petugas kesehatan sudah dijalankan oleh petugas kesehatan sesuai dengan hukum yang berlaku. ${ }^{14}$

Adapun berdasarkan pertanyaan kuesioner mengenai prosedur pelaksanaan tindakan medis banyak responden mengatakan baik karena tindakan medis yang mereka dapatkan dinilai sudah baik dan tidak ada yang merasa dirugikan. Kemudian mengenai kesesuaian tugas petugas kesehatan banyak 
responden mengatakan baik karena semua tindakan medis dilakukan oleh petugas yang memang profesional dan memang merupakan tugas dan tanggungjawabnya. Kemudian untuk pertanyaan tentang pemberlakuan persetujuan tindakan medis (Informed Consent) responden mengatakan baik karena memang setiap ada tindakan medis yang akan dilakukan, petugas kesehatan memberi pemahaman dan bertanya langsung kepada pasien atau anggota keluarganya mengenai kesiapan pasien dalam menerima dan melakukan prosedur medis tersebut. ${ }^{15}$

Selanjutnya mengenai ketersediaan sarana dan prasarana menurut responden baik karena semua alat atau kelengkapan medis yang umum diperlukan sudah tersedia dan tidak ada pasien yang ditolak karena alasan ketidaklengkapan alat dan kelengkapan medis. Dan untuk pertanyaan tenaga kesehatan yang memadai responden menilai sudah baik karena petugas kesehatan yang tersedia suda dinilai lebih banyak dari pasien sehingga berpengaruh terhadap pelayanan kesehatan yang sudah optimal. ${ }^{16}$

Dengan terpenuhinya indikator penilaian yang sejalan dengan hasil penelitian yang telah diolah maka dapat dikatakan jika penerapan hukum kesehatan pada pemberian pelayanan kesehatan di Rumah Sakit Nene Mallomo Kab. Sidrap sudah baik.

Hal ini berbanding terbalik dengan penelitian yang dilakukan oleh Muhammad Arya Harisa (2016) di Rumah Sakit Nene Mallomo yang mana memperoleh hasil bahwa jika pelaksanaan pelayanan kesehatan belum berjalan secara optimal karena pemberi layanan tidak melakukan tugasnya sesuai standar operasional prosedur dan kode etik yang berlaku sehingga hak pasien tidak terpenuhi. Dimana hasil tersebut disebabkan perbedaan metode penelitian yang dilakukan, dimana Arya Harisa memilih sampel dari berbagai aspek yaitu masing-masing 1 orang Dokter Spesialis yang memberikan pelayanan kesehatan, 1 orang Kepala Instalasi/Ruangan, 2 orang Perawat/Bidan yang memberikan pelayanan kesehatan, 1 orang Pihak Manajemen Rumah Sakit, 1 orang Direktur Rumah Sakit sebagai penentu kebijakan dan 2 orang Pasien. Sedangkan penelitian ini hanya menggunakan satu aspek sebagai sampel penelitian yaitu pasien rawat inap saja dan perbedaan yang paling terlihat yaitu penelitian sebelumnya lebih menekankan pada aspek hukum sehingga menggunakan literatur penunjang lain. ${ }^{17}$

Hasil penelitian ini juga berbanding terbalik dengan hasil Lembaga Penelitian dan Pengabdian Masyarakat (LPPM) Unhas telah mengadakan penelitian implementasi program kesehatan gratis di layanan rumah sakit berdasarkan kepesertaan, kelas perawatan, hak pelayanan sesuai petunjuk teknis program sudah berjalan baik kecuali obat yang masih ditemukan peresepan obat paten maupun pencatatan administrasi keuangan yang tidak standar. ${ }^{18}$ 


\section{KESIMPULAN DAN SARAN}

Berdasarkan penelitian yang dilakukan di Rumah Sakit Nene Mallomo Kab. Sidrap pada tanggal 15 Maret - 14 Juli 2018 maka dapat disimpulkan jika pelayanan kesehatan yang diberikan di Rumah Sakit Nene Mallomo Kab.Sidrap dalam kategori memuaskan pasien, penerapan etika dalam pemberian pelayanan kesehatan sudah baik dan sesuai dengan aturan kode etik, dan penerapan hukum kesehatan dalam pemberian pelayanan di Rumah Sakit Nene Mallomo Kab. Sidrap sudah baik dan sesuai dengan aturan perundang-undangan yang berlaku.

\section{DAFTAR PUSTAKA}

1. Dry Y. 2012. Pengertian, Tugas, dan Fungsi Etika. http://dryyeah. blogspot.co.id /2012/01/ pengertian tugas fungsi etika hak dan .html?m=1;2012. [Diakses tanggal 20 Februari 2018].

2. Akino R. 2015. Gambaran Penerapan Prinsip Etik Keperawatan Perawat Pelaksana Menurut Perspektif di IRNA Bedah di RSUP M. Djamil Padang [Skripsi]. Padang : Universitas Andalas. http://repostunand.ac.id/195/. [diakses tanggal 23 April 2018].

3. Harisa M A. 2016. Analisis Terhadap Perlindungan Hukum dalam Pelayanan Kesehatan di Rumah Sakit Nene Mallomo di Kabupaten Sidrap. [Skripsi]. Sidrap : Universitas Hasanuddin.
Berdasarkan hasil kesimpulkan, disarankan kepada para petugas kesehatan agar kiranya mempertahankan kinerja dan profesionalismenya dalam hal upaya peningkatan pelayanan kesehatan di Rumah Sakit Nene Mallomo Kab. Sidrap, diharapkan petugas kesehatan mempertahankan cara penyampaian informasi kepada pasien agar tidak terjadi kesalahpahaman, dan jumlah tenaga kesehatan serta sarana dan prasarana lebih ditingkatkan utamanya peralatan medis yang lebih canggih agar mempermudah pasien memerlukan.

4. Notoadmodjo S. 2012. Metodologi Penelitian Kesehatan. Jakarta: Rineka Cipta.

5. Aulia Dkk. 2014. Analisis Hubungan Karakteristik Pasien dengan Kepuasan Pelayanan Rawat Jalan Semarang Aye Center (SEC) Rumah Sakit Islam Sultan Agung Semarang. Semarang. Semarang : Jurnal Kesehatan Masyarakat. Vol. 2. No. 1. http://stikesayani.ac.id/publikasi/ejournal/filex/2009/200904/200904006.pdf. [Diakses tanggal 23 April 2018]

6. Ernawati. 2010. Pengaruh Pelayanan Kesehatan Terhadap Kepuasan Pasien Rawat Inap di Rumah Sakit Umum Daerah Nene Mallomo Kabupaten Sidrap. [Skripsi] : Sidrap : Universitas Muhammadiyah Parepare. 
7. Pelayanan Kesehatan serta Kebidanan. Jakarta : Penerbit Salemba Medika.

8. Manunjaya G A. 2004. Manajemen Kesehatan. Jakarta : Penerbit Buku Kedokteran.

9. Kartini. 2009. Studi Penampilan Tenaga Perawat di Ruang Rawat Inap Rumah Sakit Nene Mallomo Kabupaten Sidrap. [Skripsi]. Sidrap : Universitas Muhammadiyah Parepare.

10. Notoadmodjo S. 2010. Etika dan Hukum Kesehatan. Jakarta: Rineka Cipta.

11. Prisilia Dkk. 2015. Perbedaan Kualitas Pelayanan Keperawatan Terhadap Pasien Penerima Bantuan Iuran dan Pasien Bukan Penerima Bantuan Iuran. Manado : Jurnal Keperawatan. Vol. 3. No. 1. https://klinis.wordpress.com/2007//12/28/ kualitas-pelayanan-keperawatan/.

[Diakses tanggal 23 April 2018]

12. Satrianegara Dkk. 2012. Buku Ajar Organisasi dan Manajemen

13. Sumijatun. 2014. Persepsi Pasien Terhadap Penerapan Etika Keperawatan. Jakarta : Jurnal Keperawatan. Vol. 1. No. 2.

14. Iswandari H D. 2006. Aspek Hukum Penyelenggaraan Praktek
Kedokteran:Suatu Tinjauan Berdasarkan Undang-undang No. 9/2004 Tentang Praktek Kedokteran. Semarang : Jurnal Manajemen Pelayanan Kesehatan. Vol. 09 , No. http://jurnal.ugm.ac.id/jmpk/article/view/2 734. [Diakses tanggal 20 Februari 2018]

15. Bawono T B. 2011. Kebijakan Hukum Pidana Dalam Upaya Penanggulangan Malpraktek Profesi Medis. Jakarta: Jurnal Hukum. Vol. XXV, No.1. http://jurnal.unissula.ac.id/index.php/jurna lhukum/article/view/2014. [Diakses tanggal 23 April 2018]

16. Triwulan T. 2010, Perlindungan Hukum Bagi Pasien, Jakarta: Prestasi Pustaka

17. Wahyuningsih H P.2008.Etika Profesi Kebidanan. Yogyakarta: Fitramaya.

18. Budi. 2010. Hukum Etik Kedokteran Standar Profesi Audit Medis. https://budi399.wordpress.com/2010/11/2 2/hukum-etik-kedokteran-standar.profesi-medis-audit-medis/. [Diakes tanggal 20 Februari 2018]

19. Suryawati N. 2016. Hukum Untuk Perumah Sakitan Berdasarkan Peraturan yang Berlaku di Indonesia. Jakarta. Jurnal Hukum. Vol. 4. No. 1. 


\section{LAMPIRAN}

Tabel 1. Distribusi Karakteristik Responden Berdasarkan Umur, Jenis Kelamin, Pendidikan dan Pekerjaan pasien rawat inap Rumah Sakit Nene Mallomo

\section{Kabupaten Sidenreng Rappang}

\begin{tabular}{|c|c|c|}
\hline Karakteristik & $\mathbf{n}$ & $\%$ \\
\hline \multicolumn{3}{|l|}{ Umur (tahun) } \\
\hline$\leq 15$ & 25 & 25,3 \\
\hline $16-30$ & 25 & 25,3 \\
\hline $31-45$ & 18 & 18,2 \\
\hline $46-60$ & 16 & 16,2 \\
\hline $61-75$ & 9 & 9,1 \\
\hline$\geq 76$ & 6 & 6,1 \\
\hline Total & 99 & $\mathbf{1 0 0 , 0}$ \\
\hline \multicolumn{3}{|l|}{ Jenis Kelamin } \\
\hline Laki-laki & 41 & 41,4 \\
\hline Perempuan & 58 & 58,6 \\
\hline Total & 99 & 100,0 \\
\hline \multicolumn{3}{|l|}{ Pendidikan } \\
\hline Tidak Sekolah/Belum Sekolah & 12 & 12,1 \\
\hline Tidak Tamat SD & 11 & 11,1 \\
\hline SD & 21 & 21,2 \\
\hline SMP & 10 & 10,1 \\
\hline SMA & 35 & 35,4 \\
\hline S1 & 10 & 10,1 \\
\hline Total & 99 & 100,0 \\
\hline \multicolumn{3}{|l|}{ Pekerjaan } \\
\hline PNS/POLRI/ABRI/Pensiunan & 8 & 8,1 \\
\hline Peg./Karyawan Swasta & 6 & 6,1 \\
\hline Petani & 7 & 7,1 \\
\hline Penjual/Pedagang & 22 & 22,2 \\
\hline IRT/Tidak Kerja & 56 & 56,6 \\
\hline Total & 99 & 100,0 \\
\hline
\end{tabular}

Sumber : Data Primer Tahun 2018 
Tabel 2. Distribusi Karakteristik Responden Berdasarkan Ruang Perawatan, Kelas Perawatan, Jenis Perawatan, dan Jenis Kepesertaan pasien rawat inap Rumah

Sakit Nene Mallomo Kabupaten Sidenreng Rappang

\begin{tabular}{ccc}
\hline Karakteristik & n & \% \\
\hline Ruang Perawatan & 12 & 12,1 \\
Brotowali & 18 & 18,2 \\
KIA & 24 & 24,2 \\
Mahkota Dewa & 18 & 18,2 \\
Mengkudu & 10 & 10,1 \\
Sambiloto & 19 & 17,2 \\
Temulawak & $\mathbf{9 9}$ & $\mathbf{1 0 0 , 0}$ \\
\hline Total & & \\
Kelas Perawatan & 27 & 27,3 \\
I & 22 & 22,2 \\
II & 24 & 24,2 \\
III & 26 & 26,3 \\
VIP & $\mathbf{9 9}$ & $\mathbf{1 0 0 , 0}$ \\
\hline Total & & \\
Bedah & 10 & 10,1 \\
Interna & 32 & 32,3 \\
KIA & 19 & 19,2 \\
Saraf & 14 & 14,1 \\
Anak & 24 & 24,2 \\
\hline Total & $\mathbf{9 9}$ & $\mathbf{1 0 0 , 0}$ \\
\hline Jenis Perawatan Pasien & & 2,0 \\
Jenis & 2 & 72,7 \\
JKN/BPJS & 72 & 25,3 \\
Umum & 25 & $\mathbf{1 0 0 , 0}$ \\
\hline Total & $\mathbf{9 9}$ & \\
\hline
\end{tabular}

Sumber : Data Primer Tahun 2018

Tabel 3. Distribusi jawaban keseluruhan responden mengenai pelayanan kesehatan

\begin{tabular}{ccc}
\hline Pelayanan Kesehatan & Frekuensi & $\%$ \\
\hline Puas & 96 & 97,0 \\
Tidak Puas & 3 & 3,0 \\
\hline Total & 99 & 100,0 \\
\hline
\end{tabular}

Sumber : Data Primer Tahun 2018 
Tabel 4. Distribusi jawaban keseluruhan responden mengenai penerapan etika/kode etik

\begin{tabular}{ccc}
\hline Penerapan Etika/Kode Etik & Frekuensi & $\%$ \\
\hline Baik & 98 & 99,0 \\
Tidak Baik & 1 & 2,0 \\
\hline Total & 99 & 100,0 \\
\hline
\end{tabular}

Sumber : Data Primer Tahun 2018

Tabel 5. Distribusi jawaban keseluruhan responden mengenai penerapan hukum kesehatan

\begin{tabular}{ccc}
\hline Penerapan Hukum Kesehatan & Frekuensi & $\%$ \\
\hline Baik & 96 & 97,0 \\
Tidak Baik & 3 & 3,0 \\
\hline Total & 99 & 100,0
\end{tabular}

Sumber : Data Primer Tahun 2018 